Abstracta Iranica Abstracta Iranica

Revue bibliographique pour le domaine irano-aryen

Volume 32-33 | 2013

Comptes rendus des publications de 2009-2010

\title{
Ellen Rehm. The Classification of Objects from the Black Sea Region Made or Influenced by the Achaemenids
}

\section{Astrid Nunn}

\section{(2) OpenEdition}

1 Journals

\section{Édition électronique}

URL : http://journals.openedition.org/abstractairanica/40405

DOI : 10.4000/abstractairanica.40405

ISSN : 1961-960X

Éditeur :

CNRS (UMR 7528 Mondes iraniens et indiens), Éditions de l'IFRI

\section{Édition imprimée}

Date de publication : 1 décembre 2013

ISSN : 0240-8910

\section{Référence électronique}

Astrid Nunn, «Ellen Rehm. The Classification of Objects from the Black Sea Region Made or Influenced by the Achaemenids », Abstracta Iranica [En ligne], Volume 32-33 | 2013, document 110, mis en ligne le 01 juillet 2016, consulté le 27 septembre 2020. URL : http://journals.openedition.org/abstractairanica/ 40405 ; DOI : https://doi.org/10.4000/abstractairanica.40405

Ce document a été généré automatiquement le 27 septembre 2020.

Tous droits réservés 


\title{
Ellen Rehm. The Classification of Objects from the Black Sea Region Made or Influenced by the Achaemenids
}

\author{
Astrid Nunn
}

\section{RÉFÉRENCE}

Ellen Rehm. « The Classification of Objects from the Black Sea Region Made or Influenced by the Achaemenids », in : Jens Nieling, Ellen Rehm, eds., Achaemenid impact in the Black Sea. Communication of powers. Aarhus, Aarhus University Press, 2010, p.

161-194. (Black Sea Studies, vol. 11).

1 Que veut dire influence dans un art achéménide si éclectique? L'A. part des caractéristiques les plus locales et se rapproche en trois étapes de l'art du centre achéménide. Les noms qu'elle a choisis pour ces trois étapes - «court-style art» («Hofstil»), « satrapal art » et « Perso-barbarian art » - sont expressément « catchy » pour permettre une référence rapide. L'A. en livre un historique et il va sans dire qu'il n'est pas toujours facile de ranger les objets dans l'une ou l'autre catégorie. À la première catégorie appartiennent des bracelets en or de Vani, des sceaux-cylindres de Kertch et un vase d'argent de Rozovec. «L'art satrapique », très proche de l'art aulique, comprend des bijoux, un rython de Borovo et plusieurs vaisselles métalliques dont l'amphore de Duvanli. Le même type d'objets, mais plus marqué par l'art local ou grec ainsi qu'un chapiteau à protomes taurins de Zichiagora (Géorgie) se trouvent dans la troisième catégorie. 


\section{AUTEURS}

\section{ASTRID NUNN}

Université de Munich 